\title{
Nutritional assessment of selected hypercholesterolemic adult women (30-60 years) of Cheriyanad panchayath of Alapuzha district
}

\author{
Renjini. M.R, \\ Department of Food Science and Quality Control N.S.S. Hindu College, Changanacherry, Kerala,India
}

\begin{abstract}
The present study was conducted to assess the nutritional status of selected hypercholesterolemic adult women of 30-60 years belonging to Cheriyanad panchayath of Alapuzha district. Data on socio economic status, health status, life style and physical activity pattern and dietary pattern were collected using a prestructured interview schedule. Biochemical assessment to know the prevalence of hypercholesterolemia and anthropometric measures and 24 hour recall to assess the nutritional status were done. Biochemical assessment revealed that hypercholesterolemia was higher among the age group 51-60 years indicating the effect of menopause. The study clearly depicted the lack of physical activity and intake of diet rich in fats and calories were important contributing factors to the higher blood cholesterol levels in the subjects.
\end{abstract}

Keywords: Hypercholesterolemia, Nutritional status, Adult women

\section{Introduction}

Human diseases are mostly the result of heredity, environment or food. It is not possible to change heredity, it is difficult to change environment but it is relatively easy to change food habits. Life style diseases become ever more widespread as countries become more industrialized. Unlike communicable diseases, life style diseases are preventable and avoidable, changing our life style can prevent such diseases. It has already been reported that dietary habits usually influence blood lipids (Trichopoulou et al., 1995). Hyperlipidemia is largely under treated in women. A survey conducted by the society for Women's Health Research reveals that women need a little more education when it comes to heart disease and their cholesterol (Jennifer, 2008). This study sheds light on the fact that, although women are aware of the consequences of high cholesterol, misinformation is still present. This misinformation among women is troubling, since heart disease is the leading cause of death in women, and persistently high cholesterol levels can contribute to heart disease. And hence the present study was conducted among the selected hypercholesterolemic adult women to study the socio economic, life style, physical activity and dietary pattern and to impart nutritional knowledge using a developed pamphlet showing the causes, risk factors and management of the disease.

\section{Materials And Methods}

Cheriyanad panchayath of Alapuzha district was the selected area of study. From 300 adult women of 30-60 years, 108 were found to be hypercholesterolemic with whom the study was further carried out. Data on socio economic status, health status, life style and physical activity and food consumption pattern were collected using a prestructured interview schedule. Biochemical assessment for the total blood cholesterol levels of the subjects was done with the help of a laboratory technician to know the prevalence of hypercholesterolemia. Anthropometric measurements like height, weight, waist hip circumferences (WHR) were collected using standard procedures recommended by Jelliffe (1988). Nutritional status based on BMI was evaluated using internationally accepted World Health Organization BMI guidelines (WHO, 2004).

\section{Result And Discussion}

Majority of the subjects (76\%) belonged to 51-60 years of age, whereas 18 percent belonged to $41-50$ and only six percent were 30-40. American Heart Association (2007) in a study reported that at above the age of 45 , women had total blood cholesterol of $200 \mathrm{mg} / \mathrm{dl}$ or higher. Majority of the subjects (82\%) were Hindus. Only $18 \%$ were Christians. Of the 108 subjects, 76 percent came from nuclear family, while only 24 percent from joint family. It was found out that 36 percent were graduates, 11 percent were post graduates, and 21 percent had completed their Pre degree course, 17 percent High School and 15 percent Lower primary.

Of the selected subjects 72 percent belonged to non working category and 79 percent from middle income families with a family income of Rs.4500-7500 per month (based on HUDCO classification, 2002).It was observed that 19 percent of the subjects had the heredity of the disease whereas the rest ( $81 \%)$ had no history of hypercholesterolemia. Only twenty percent checked their cholesterol levels once in a month regularly where three percent twice in a month. Thirty six percent of the subjects tested the cholesterol levels only once in 
2 months while 39 percent occasionally and two percent rarely. Seventeen percent were chronic sufferers of hypercholesterolemia with more than 10 years. Twenty two per cent were newly detected, that is, disease identified within a year. Forty three per cent of the subjects were suffering from hypercholesterolemia for 1-5 years, whereas 19 percent for more than 5 years.

The initial reasons for checking the blood cholesterol level in 76 percent of the subjects was joint pains mainly in knee joints. That is, they were suggested to test their blood cholesterol level due to joint pains mainly in knee joints, where as 11 percent due to muscular pains. Six percent of the subjects test their cholesterol levels because of diabetes and one percent tests their cholesterol level due to heart disease. Six percent tested blood cholesterol level due to hypertension..Forty six percent of selected subjects suffered from hypertension and 19 percent from diabetes whereas other complications like osteoporosis, heart diseases and anemia were seen in four per cent and one percent by the subjects respectively. Weight gain was noticed is 77 percent of the subjects whereas 20 per cent experienced reduction in body weight. Only three per cent had reported either increase or decrease in body weight. According to Evans (2002), after menopause there appears to be an accelerated increase in fat mass. Majority were consuming medicines.

The study clearly showed that majority of the hypercholesterolemic subjects were leading a sedentary life that is, by 81 percent. Nineteen per cent had moderate activity and none with heavy activity. Only six percent had the habit of exercise and walking is the type of exercise followed by them. Ninety four percent never had the habit of regular exercise. Twenty six percent of the samples spend their leisure time by sleeping where as the majority (57\%) by watching T.V. Only eight percent involved in reading books, three percent in stitching, two percent in gardening and four percent in others (social activities like Kudumbasree, Ayalkootam. etc.) According to National Heart, Lung and Blood Institute (2004), being inactive can cause elevated cholesterol levels.

Mean Body Mass Index of the subjects revealed that majority (79\%) belonged to over weight category. Twenty per cent had their BMI normal and none of the subjects were undernourished and only one per cent was found to be obese. Here it is clearly evident from Table I that a majority ( 8 percent) of the subjects were prone to obesity. Abdominal obesity seems to be increasing along with the age and is more prevalent in 41-50 years age group. WHO STEPS states that abdominal obesity is defined as a waist-hip ratio above 0.85 for females (WHO, 2011).

It was observed that the prevalence of high blood cholesterol levels found commonly in nonvegetarians that is, 77 percent were non vegetarians. Majority of subjects ( 87 percent) followed three meal pattern and no subjects had the habit of regular outside food consumption. The frequency of consumption of various food items by the subjects clearly shows that all the subjects had a daily consumption of cereals. A majority of the subjects (60 percent) consumed pulses twice a week while 11 percent and 12 percent consumed pulses thrice a week and once a week respectively. Seventeen percent of the subjects consumed pulses daily. Consumption of green leafy vegetables was only once in a week among 41 percent of the subjects where as 59 consumed very rarely. Fifty four percent consumed other vegetables daily, 20percent thrice a week and five percent once in a week. Roots and tubers were consumed daily by 11 percent, thrice a week by 28 percent, twice a week by 14 percent and once a week by 22 percent. Eighteen per cent consumed roots and tubers rarely and seven per cent never consumed roots and tubers intentionally to avoid starchy foods. Fruits were consumed daily by only eight percent, thrice a week by 21 per cent, twice a week by 17 per cent and once a week by 26 per cent. Nineteen per cent consumed fruits rarely and nine per cent never consumed.

Milk and milk products were consumed daily by 94 percent and not at all by six percent. Twenty six percent consumed fish and flesh foods daily and two percent had a diet completely devoid of fish and flesh foods. Butter, ghee and oil daily consumed by seven percent, 69 per cent rarely and 23 per cent never consumed. Seventy two percent consumed sugar and jaggery daily, 13 per cent rarely and 15 per cent not at all. Of the 101 non vegetarian patients, 68 percent preferred fish mostly. Thirteen percent liked to consume poultry. Mutton is preferred by 18 percent and only one percent liked beef.

Of the subjects, 96 percent used coconut oil for cooking, three percent used sun flower oil and only one percent used mixed oils. According to Srilakshmi (2006), coconut oil contains high amount of saturated fat, the high intake of which increases plasma cholesterol. Sixty six percent of the subjects had the habit of nibbling. Of them 44 percent used fried items, two percent used fruits and vegetables and 12 percent used sweets for nibbling. Thirty four percent of the subjects never had the habit of nibbling.

Fruits and vegetables consumption was very rare among the subjects, especially in the raw form. Nobody drank milk as such, only in the form of tea or coffee, the used milk was not defatted. Most subjects tried to avoid egg yolk and used only skin removed chicken. They were not at all concerned about the over consumption of coconut and coconut oil. Nobody was aware about the importance of fibre rich foods or the need to avoid friedfoods. AccordingtoTangJL et. al., (1998), in practice, dietary advice canprovideamodestdecreaseincholesterollevelsandmay be sufficient in the treatment of mildly elevated cholesterol. 
Fig 1 depicts details on the mean nutrient intake of the subjects clearly shows that the fat intake was too higher $(+155)$ than the recommended intake. Hooper et. al, (2002) recommended that reducing dietary fat is recommended to reduce total blood cholesterol and LDL in adults. Similarly their energy too $(+27.47)$ where as their fibre intake was very less (-29.2). A deficit intake was observed in case of Vitamin C and Iron by -13 and 8.33 respectively. The subjects also had an excess intake of protein $(+14)$, Calcium $(+8.78)$ and retinol $(+13.73)$.

Table II shows that the average level of the total cholesterol in the subjects was $225.4 \mathrm{mg} / \mathrm{dl}$ which is 'border line high' where the normal value is less than 200. The mean value of LDL cholesterol of the selected hypercholesterolemic adult women was $148.9 \mathrm{mg} / \mathrm{dl}$ which also has in 'border line high'. The level of triglycerides in the subjects was $168.13 \mathrm{mg} / \mathrm{dl}$ against the normal value of less than 150, and that of HDL cholesterol is $43 \mathrm{mg} / \mathrm{dl}$ against the normal value of greater than 60 which is okay but not optimal (ATP III Guidelines at - A - Glance Quick Desk Reference, National Cholesterol Education Program, 2009).

\section{V. Figures And Tables \\ TABLE 1}

Classification of subjects based on Waist Hip Ratio

\begin{tabular}{|c|c|c|c|c|c|c|}
\hline \multirow[b]{2}{*}{ Waist Hip Ratio } & \multicolumn{2}{|c|}{$\begin{array}{c}\mathrm{N}=7 \\
30-40 \text { yrs }\end{array}$} & \multicolumn{2}{|c|}{$\begin{array}{c}\mathrm{N}=19 \\
41-50 \mathrm{yrs}\end{array}$} & \multicolumn{2}{|c|}{$\begin{array}{c}\mathrm{N}=82 \\
51-60 \mathrm{yrs}\end{array}$} \\
\hline & Number & Percentage & No. & $\%$ & No. & $\%$ \\
\hline 0.7 (Normal) & 3 & 43 & 4 & 21 & 7 & 9 \\
\hline $\begin{array}{l}0.71-0.8 \text { (Femoral glutal } \\
\text { obesity) }\end{array}$ & 3 & 43 & 6 & 32 & 19 & 23 \\
\hline $\begin{array}{l}0.81-8.9 \\
\text { (Abdominal obesity) }\end{array}$ & 1 & 14 & 9 & 47 & 56 & 68 \\
\hline Total & 7 & 100 & 19 & 100 & 82 & 100 \\
\hline
\end{tabular}

Table - II

Details on mean lipid profile of the subjects

\begin{tabular}{|l|c|c|}
\hline \multicolumn{1}{|c|}{$\mathbf{N}=\mathbf{1 0 8}$} \\
\hline Element & Normal value $(\mathrm{mg} / \mathrm{dl})$ & $\begin{array}{l}\text { Mean value of the samples } \\
(\mathrm{mg} / \mathrm{dl})\end{array}$ \\
\hline Total Cholesterol & $<200$ & 225.4 \\
\hline LDL Cholesterol & $<100$ & 148.9 \\
\hline Triglycerides & $<150$ & 168.13 \\
\hline HDL Cholesterol & $>60$ & 43 \\
\hline
\end{tabular}

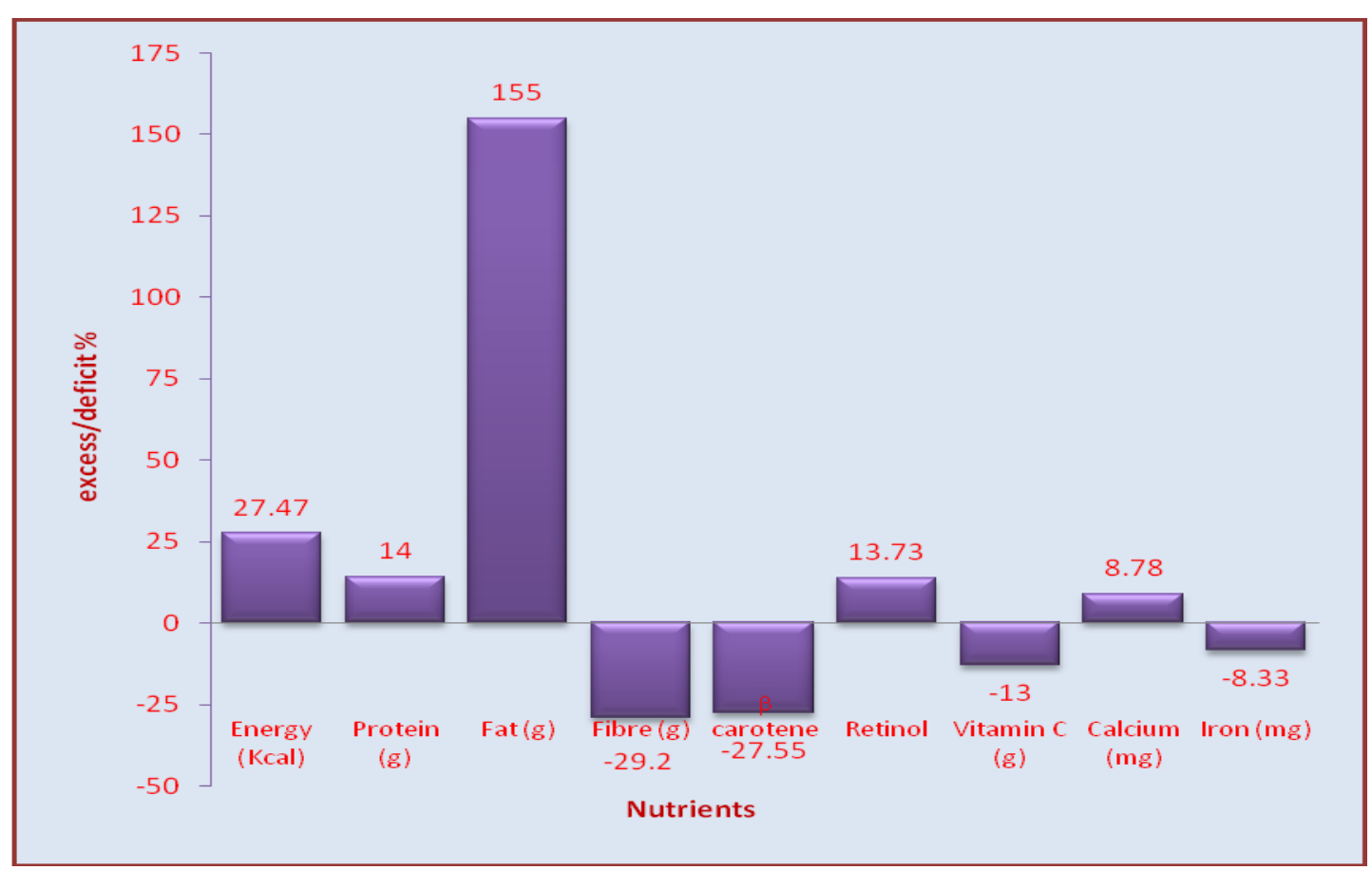

PERCENTAGE WISE DISTRIBUTION OF EXCESS/ DEFICIT NUTRIENT INTAKE BY THE SAMPLES 


\section{Conclusion}

Life style related diseases have been increasing and accounting for more than 16 percent of all deaths. These diseases can be lowered with the changes in life style. Hypercholesterolemia is a major women's health issue especially among the middle aged. So it is important to modify the diet and life style of women and for that, regular and proper awareness and dietary intervention programmes are required.

\section{Reference}

[1] Trichopoulou A,Kouris-Blazos A,Wahlgvist M,Gnardellis C,Lagiou P,Poly chronopoulos E,Vassilakou T,Lipworth L and Trichopoulos D: Diet and overall survival in elderly people.Brit.Med.J 1995,311:1457-1460.

[2] Jelliffe D.B. The assessment of nutritional status of the community, World Health Organization, Geneva, 1988, 69: 193-197

[3] WHO Expert Consultation. Appropriate body mass index for Asian populations and its implications for policy and intervention strategies.Lancet.2004;363:157-163.

[4] SrilakshmiL,Nutrition,Science NewDelhi, NewAgeInternational(P)Limited Publishers, $2^{\text {nd }}$ Edition, (2006)

[5] Tang JL, Armitage JM, Lancaster T, Silagy GA Fowler GH and Neil HA "Systematic review of dietary intervention trials to lower blood total cholesterol in free living subjects $B M J$ (1998), 316 (7139): 1313-20 Retrieved 2010-11-02.

[6] Hooper L, Summerbell C D, Thompson R et.al), Reduced or modified dietary fat for preventing cardiovasculardiseases,Cohrane.,(2012) Database Syst.Rev.5:CD002137

[7] http:|//whqlibdoc.who.int./publications/2011/9789241501491 eng. 